\title{
Properties of Ti-Al intermetallic coatings obtained by electrospark processing in a mixture of $\mathrm{Ti}$ and $\mathrm{Al}$ granules
}

\author{
A. A. Burkov ${ }^{\dagger}$, M. A. Kulik \\ †burkovalex@mail.ru
}

Institute of Materials Science, Khabarovsk Scientific Centre, FEB RAS, 153 Tikhookenskaya St., Khabarovsk, 680042, Russia

Titanium alloys attract a wide attention of researchers due to the unique combination of low density and high strength, hardness, corrosion resistance, biocompatibility, etc. Therefore, the study of new methods for processing titanium and the development of coatings from titanium intermetallic compounds seems relevant. In this paper, we consider the properties of Ti-Al coatings deposited by electrospark processing of a Ti6Al4V titanium alloy in a mixture of granules of titanium and aluminum in five different ratios with an aluminum content of 24 to 87 at.\%. X-ray phase analysis showed the evolution of the intermetallic composition of the coatings with an increase in the aluminum content in the mixture of granules from the $\mathrm{AlTi}_{3}$ to $\mathrm{Al}_{3} \mathrm{Ti}$ phase. Potentiodynamic polarization tests in a $3.5 \% \mathrm{NaCl}$ solution showed that coatings could improve the corrosion resistance of the Ti6Al4V alloy. A high-temperature gas corrosion test for 100 hours at a temperature of $900^{\circ} \mathrm{C}$ showed that coated samples were oxidized 1.1-3.4 times less than the Ti6Al4V alloy. The best properties was exhibited by the coating with the highest aluminum content. The coatings had an increased microhardness of $6.4-9.4 \mathrm{GPa}$. Coatings with a closer ratio of titanium to aluminum had the highest hardness. The wear resistance of the coatings in the dry slip mode at loads of 10 and $25 \mathrm{~N}$ was 4-27 and 6-36 times, respectively, higher than that of the Ti6Al4V alloy. The wear rate of the coatings decreased with increasing titanium concentration. The dependence of the wear resistance of coatings on their hardness for the obtained Ti-Al coatings is exponential, which is consistent with the Archard law.

Keywords: titanium aluminum intermetallic compounds, Ti6Al4V alloy, wear, oxidation resistance.

УДК: $621.762 ; 537.523 .4$

\section{Свойства Ti-Al интерметаллидных покрытий, полученных электроискровой обработкой в смеси гранул Ti и $\mathrm{Al}$}

\author{
Бурков А. А. ${ }^{\dagger}$ Кулик М. А. \\ Институт материаловедения Хабаровского НЦ ДВО РАН, ул. Тихоокеанская, 153, Хабаровск, 680042, Россия
}

Титановые сплавы привлекают широкое внимание исследователей из-за уникального сочетания низкой плотности, высокой прочности и твердости, а также, коррозионной устойчивости и биосовместимости. Поэтому изучение новых методов обработки титана и создания покрытий из интерметаллидов титана представляется актуальным. В настоящей работе рассматриваются свойства Ti-Al покрытий, осажденных методом электроискровой обработки титанового сплава Ti6Al4V в смеси гранул из титана и алюминия в пяти различных соотношениях с содержанием алюминия от 24 до 87 ат.\%. Рентгенофазовый анализ показал эволюцию интерметаллидного состава покрытий с ростом содержания алюминия в смеси гранул от фазы $\mathrm{AlTi}_{3}$ до $\mathrm{Al}_{3} \mathrm{Ti}$. Потенциодинамические поляризационные испытания в 3.5\%-ном растворе $\mathrm{NaCl}$ показали, что покрытия могут улучшить коррозионную стойкость сплава Ti6Al4V. Испытание на высокотемпературную газовую коррозию в течение 100 часов при температуре $900^{\circ} \mathrm{C}$ показало, что образцы с покрытиями были окислены в 1.1-3.4 раза меньше, чем сплава Ti6Al4V. Лучшие свойства показало покрытие с наибольшим содержанием алюминия. Покрытия имели повышенную микротвердость 6.4-9.4 ГПа. Наибольшей твердостью обладали покрытия с более близким соотношением титана к алюминию. Износостойкость покрытий в режиме сухого скольжения при нагрузках 10 и 25 Н была в 4 - 27 и 6 - 36 раз выше соответственно, чем у сплава Ti6Al4V. Скорость износа покрытий снижалась с ростом концентрации титана. Зависимость износостойкости покрытий от их твердости для полученных Ti-Al покрытий носит экспоненциальный характер, что согласуется с законом Архарда.

Ключевые слова: интерметаллиды титана-алюминия, сплав Ti6Al4V, коррозионная стойкость, износ, жаростойкость. 


\section{1. Введение}

Интерметаллиды титана-алюминия $\mathrm{Ti}_{x} \mathrm{Al}_{y}$ часто рассматриваются исследователями в качестве материала покрытий для титановых сплавов [1-3]. Они имеют ряд преимуществ в качестве материала для нанесения жаростойких и износостойких покрытий на титановых сплавах, поскольку обеспечивают высокую адгезию с подложкой. В последнее время для создания интерметаллидных покрытий применяют различные методы осаждения: диффузионное насыщение, вакуумно-дуговое испарение, ионную имплантацию, лазерную наплавку, газоплазменное напыление и др. [4-9]. В данной работе использована технология электроискрового легирования, которая основана на явлении полярного переноса материала с анода на катод при воздействии микродуговых электрических разрядов [10,11]. Проведенные нами исследования показали, что метод электроискровой обработки может быть успешно применен для создания покрытий из алюминидов титана с различными стехиометрическими соотношениями [12]. Как показывает ряд исследований [4-9,13], Ti-Al покрытия без армирующих добавок относительно слабо улучшают сопротивляемость титановых сплавов к изнашиванию и высокотемпературной газовой коррозии. В предыдущих исследованиях по нанесению интерметаллидных покрытий в гранулах из алюминия и титана было показано, что состав покрытий на титановом сплаве $\mathrm{Ti} 6 \mathrm{Al} 4 \mathrm{~V}$ напрямую зависит от исходного весового соотношения между гранулами [14]. Цель настоящей работы заключалась в изучении влияния соотношения $\mathrm{Ti}$ и $\mathrm{Al}$ в смеси гранул на износоустойчивость, жаростойкость и антикоррозионные свойства интерметаллидных покрытий, полученных методом электроискровой обработки в гранулах из титана и алюминия.

\section{2. Материалы и методы исследования}

Гранулы были изготовлены в форме цилиндров длиной $4 \pm 1$ мм из прутков алюминиевого сплава 1188 и титанового сплава ВТ1-00 диаметром $4 \pm 0.5$ мм (Табл. 1). Из этих гранул были сформированы пять смесей с разной концентрацией алюминия от 24 до 88 ат.\% (Табл. 2). Концентрация алюминия и титана в смеси гранул рассчитывалась исходя из данных по составу сплавов и их массовой доле в смеси гранул. Покрытия осаждали на образцы в форме цилиндров диаметром 12 мм и высотой 10 мм из сплава Ti6Al4V с помощью установки, схема которой показана на Рис. 1.
Образец-подложку закрепляли в центре внутренней полости стального контейнера, и добавляли гранулы. Контейнер располагается под углом $45^{\circ}$ к плоскости стола и приводится во вращение с помощью электродвигателя. Положительный потенциал от генератора подавали на контейнер, а отрицательный - на подложку. Во время прохождения разрядов контейнер вращался со скоростью 60 об/мин, катод-подложка - с аналогичной скоростью в обратном направлении. Разрядные импульсы тока прямоугольной формы имели среднюю амплитуду 110 А при напряжении 30 В. Длительность импульсов составляла 100 мкс, частота повторения 1 кГц. Общая продолжительность электроразрядной обработки - 10 мин. Для предотвращения азотирования и окисления поверхности образцов в рабочий объем контейнера подавали защитный газ - аргон. По данным наших предыдущих работ по осаждению покрытий из металлических стекол было показано, что гранулам требуется определенное время на приработку для охвата

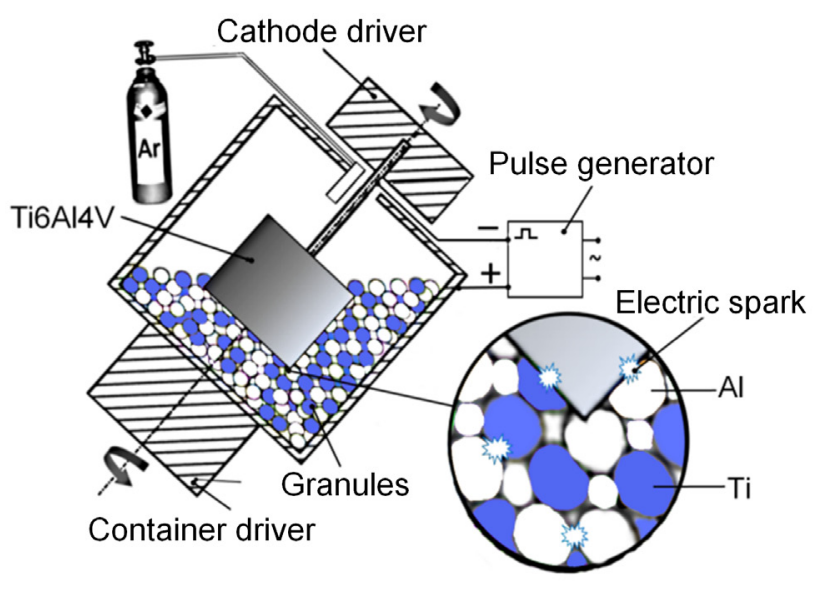

Pис. 1. (Color online) Схема электроискровой установки для осаждения покрытий в смеси гранул.

Fig. 1. (Color online) Scheme of an electrospark installation for deposition of coatings in a mixture of granules.

Табл. 2. Состав смеси гранул и обозначение покрытий. Table 2. Granule mixture composition and designation of coatings.

\begin{tabular}{|c|c|c|c|c|c|}
\hline $\begin{array}{c}\text { Обозначение/ } \\
\text { Designation }\end{array}$ & 24AlTi & 31AlTi & 50AlTi & 73AlTi & 88AlTi \\
\hline $\begin{array}{c}\text { C(Al), ат.\% } \\
\text { C(Al), at.\% }\end{array}$ & 24.21 & 30.99 & 49.93 & 72.81 & 87.39 \\
\hline $\begin{array}{c}\text { C(Ti), ат.\% } \\
\text { (Ti), at.\% }\end{array}$ & 73.32 & 68.97 & 47.73 & 25.87 & 11.94 \\
\hline
\end{tabular}

Табл. 1. Химический состав сплавов.

Table 1. Chemical composition of alloys.

\begin{tabular}{|c|c|c|c|c|c|c|c|c|c|}
\hline \multirow{2}{*}{ Сплав/Alloy } & \multicolumn{9}{|c|}{ Состав, вес.\% / Composition, wt.\% } \\
\hline \multirow{2}{*}{1188} & $\mathrm{Al}$ & $\mathrm{Si}$ & $\mathrm{V}$ & $\mathrm{Zn}$ & $\mathrm{Ga}$ & $\mathrm{Cd}$ & $\mathrm{Ti}$ & $\mathrm{Mn}$ & $\mathrm{Mg}$ \\
\cline { 2 - 11 } & 99.871 & 0.056 & 0.026 & 0.012 & 0.011 & 0.0023 & 0.005 & 0.005 & 0.011 \\
\hline \multirow{2}{*}{$\mathrm{BT} 1-00$} & $\mathrm{Ti}$ & $\mathrm{Fe}$ & $\mathrm{O}$ & $\mathrm{H}$ & $\mathrm{Si}$ & $\mathrm{C}$ & $\mathrm{N}$ & - & - \\
\cline { 2 - 10 } $\mathrm{VT} 1-00$ & 99.58 & 0.15 & 0.1 & 0.008 & 0.08 & 0.05 & 0.04 & - & - \\
\hline
\end{tabular}


поверхности всех гранул электрическими разрядами и выравнивания состава поверхности всех гранул одного сорта [15]. Поэтому исследования проводились с использованием гранул, приработанных в течение 1 часа. Продолжительность нанесения одного покрытия составляла 8 минут.

Структура покрытий исследовались с применением рентгеновского дифрактометра ДРОН-7 в $\mathrm{Cu}_{\mathrm{Ka}}$-излучении. Среднюю толщину покрытий определяли методами металлографии по поперечному сечению покрытий с использованием соответствующих травителей на основе НF и оптической микроскопии. Элементный состав образцов был изучен с помощью растрового электронного микроскопа (СЭМ) Sigma 300 VP, оснащенного микрорентгеноспектральным анализатором INCA Energy. Твердость покрытий измерялась на микротвердомере ПМТ-3М при нагрузке $0.5 \mathrm{H}$ по методу Виккерса. Коэффициент трения и износостойкость покрытий исследовались по стандарту ASTM G99-04 при сухом трении скольжения с применением контртела в виде диска из быстрорежущей стали Р6М5 на скорости $0.47 \mathrm{Mc}^{-1}$ при нагрузках 10 и $25 \mathrm{H}$, соответственно. Электрохимические поляризационные испытания проводились в 3.5-процентном растворе $\mathrm{NaCl}$ в трехэлектродной ячейке с использованием потенциостата Р-2X. В качестве электрода сравнения использовался стандартный хлорсеребряный электрод. Контр-электрод представлял собой платиновый электрод «ЭТП-02», а в качестве рабочего электрода выступали образцы с покрытием и сплав Ti6Al4V. Площадь контакта образцов с электролитом составляла $1 \mathrm{~cm}^{2}$. Сканирование осуществлялось со скоростью $3 \mathrm{MBc}^{-1}$ в диапазоне $1.5-0.5 \mathrm{~B}$. Для обеспечения воспроизводимости результатов выполняли 5 измерений каждого образца. Испытания на жаростойкость проводили в печи при температуре $900^{\circ} \mathrm{C}$ на воздухе. Общее время тестирования составляло 100 часов. Образцы выдерживали при заданной температуре в течение $\sim 6$ ч, затем удаляли и охлаждали в эксикаторе до комнатной температуры. Во время испытания все образцы помещались в корундовый тигель для учета массы отслоившихся оксидов. Изменение массы всех образцов измеряли с использованием лабораторных весов с чувствительностью 0.1 мг.

\section{3. Результаты и обсуждение}

Участки рентгеновских дифрактограмм покрытий показаны на Рис. 2. Из него следует, что с ростом доли алюминия в смеси гранул повышается содержание богатых им фаз в составе покрытий. Так в составе смеси 24AlTi отношение алюминия к титану составляет примерно 1:3, и соответственно, в составе данного покрытия преобладают фазы богатые титаном $\mathrm{AlTi}_{3}$ и $\mathrm{AlTi}_{2}$. Характерно, что в составе данного покрытия присутствует нитрид титана, несмотря на использование аргона. Это можно объяснить высоким сродством титана к азоту, который проникал в реактор сквозь встречный поток выходящего аргона. Данные микрорентгеноспектрального

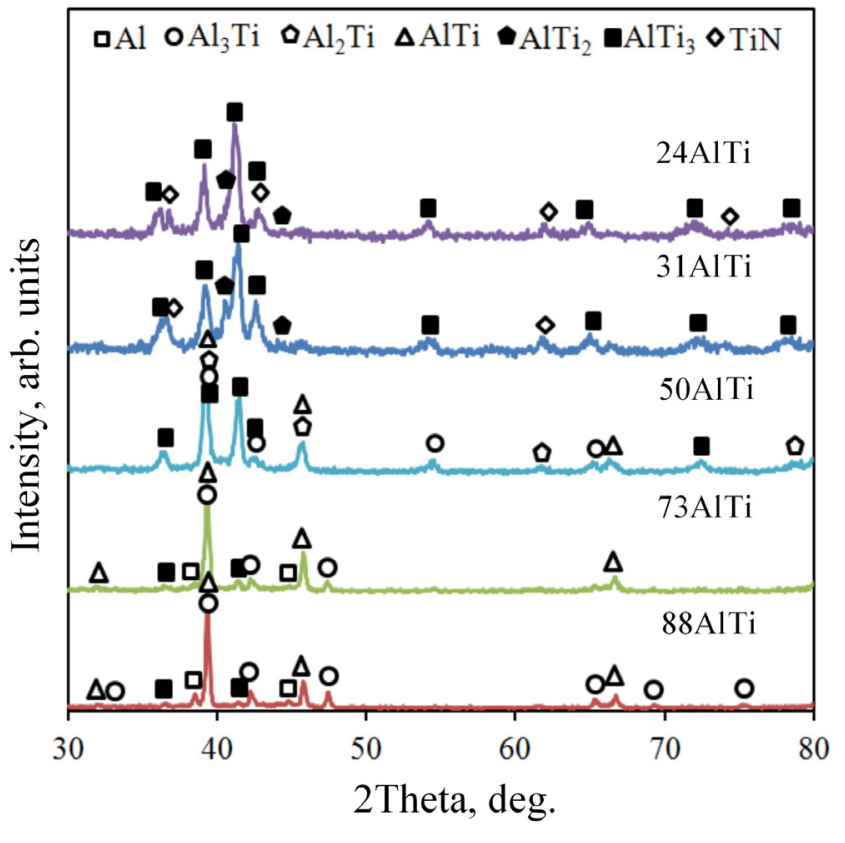

Pис. 2. (Color online) Участки рентгеновских дифрактограмм осажденных покрытий.

Fig. 2. (Color online) X-ray phase analysis of the deposited coatings.

анализа не показали наличие азота на поверхности покрытия, что говорит о незначительном количестве азота в данном покрытии. Вместе с тем, присутствие $\mathrm{TiN}$ на дифракционном спектре указывает на высокую чувствительность дифракцонного метода к TiN, на фоне интерметаллидов Ti-Al. Если рассматривать покрытие 50AlTi, где в смеси гранул соотношение алюминия к титану составляет $1: 1$, то в его составе преобладает интерметаллид TiAl, но также присутствуют фазы более и менее богатые титаном. В составе покрытий 73AlTi и 88AlTi преобладают фазы $\mathrm{Al}_{3} \mathrm{Ti}$ и AlTi, а также наблюдаются следы фаз Al и $\mathrm{AlTi}_{3}$. Характерно, что фаза $\mathrm{AlTi}_{3}$ присутствовала на дифракционных спектрах всех образцов. Это можно объяснить участием титана подложки в формировании покрытий. В целом можно констатировать химическую неоднородность покрытий, где на их различных участках могут одновременно присутствовать интерметаллиды, богатые титаном $\left(\mathrm{AlTi}_{3}\right)$ и богатые алюминием $\left(\mathrm{Al}_{3} \mathrm{Ti}\right)$. Это объясняется тем, что формирование интерметаллидных соединений происходит как на поверхности гранул каждого сорта, так и на поверхности подложки [14].

Толщины покрытий снижалась с ростом содержания алюминия в смеси гранул в диапазоне от 52 до 28 мкм

Табл. 3. Толщины покрытий.

Table 3. Thickness of coatings.

\begin{tabular}{|c|c|c|c|c|c|}
\hline Покрытие/Coating & 24AlTi & 31AlTi & 50AlTi & 73AlTi & 88AlTi \\
\hline $\begin{array}{c}\text { Толщина, мкм } \\
\text { Thickness, } \mu \mathrm{m}\end{array}$ & 51.9 & 30.6 & 36.2 & 28.5 & 28.4 \\
\hline $\begin{array}{c}\text { Стандартное откл., мкм } \\
\text { Standard deviation, } \mu \mathrm{m}\end{array}$ & 18.4 & 13.8 & 10.9 & 11.4 & 10.2 \\
\hline
\end{tabular}


(Табл. 3), что можно объяснить более низкой температурой плавления фаз богатых алюминием, и соответственно, низкой электроэрозионной стойкостью.

На Рис. 4 показано изменение массы образцов и сплава Ti6Al4V при температуре $900^{\circ} \mathrm{C}$. Фактически это масса кислорода, зафиксированного на поверхности образцов в виде оксидов, прежде всего оксида титана (IV) в модификации рутила. За 100 часов испытаний образцы с покрытиями в 1.1-3.4 раза меньше подверглись окислению, чем сплав Ti6Al4V, вследствие ограничения контакта кислорода с подложкой. Скорость окисления образцов с покрытиями во время выдержки снижалась. Это объясняется увеличением толщины оксидной пленки по мере высокотемпературной экспозиции согласно параболическому закону. В работе [13] рассматривается близкая выборка Ti-Al интерметаллидных покрытий, полученных электронно-лучевым методом. В ней авторы получили схожие результаты по исследованию жаростойкости и защитному эффекту покрытий. Так лучшую жаростойкость показало покрытие с наименьшим содержанием титана.

На Рис. 3 b показаны результаты потенциодинамических поляризационных испытаний образцов. Поляризационные кривые для всех покрытий и сплава Ti6Al4V располагались в достаточно узкой области, чтобы визуально делать оценки. Поэтому были рассчитаны ток коррозии $\left(I_{\text {corr }}\right)$ и сопротивление поляризации $\left(R_{\mathrm{p}}\right)$ по наклонам Тафеля [16]. Результаты расчетов приведены в Табл. 4. При этом, образцы с более высоким содержанием алюминия (50AlTi-88AlTi) показали более высокие значения сопротивления поляризации, но более высокий потенциал коррозии, что закономерно, поскольку алюминий формирует более плотную оксидную пленку, но при этом является более активным металлом, по сравнению с титаном. Образцы с более высоким содержанием титана (24AlTi-31AlTi) имели низкое $R_{\mathrm{p}}$ и сопоставимый потенциал коррозии $\left(E_{\text {corr }}\right)$. Ток коррозии $\left(I_{\text {corr }}\right)$ всех покрытий был незначительно выше, чем у исходного сплава, что можно интерпретировать более высокой шероховатостью образцов (Табл. 3), и соответственно более развитой границей раздела металл-электролит.

Микротвердость покрытий была выше, чем у исходного сплава Ti6Al4V в 1.9-2.8 раза (Рис. 4 a). Несмотря на то, что в составе сплава Ti6Al4V содержание титана выше, чем в интерметаллидах, твердость последних примерно в два раза выше, чем у сплава [17]. C повышением концентрации алюминия твердость покрытий сперва повышалась, а затем снижалась. Это согласуется с литературными данными [18,19], где наибольшая твердость указывается для интерметаллида с соотношением $\mathrm{Ti}$ и $\mathrm{Al}$ близким к эквимолярному. Кроме того, повышенные значения твердости покрытий, нанесенных в смеси гранул с высоким содержанием титана, объясняется присутствием небольшого количества нитрида титана [20] (Рис. 2).

Как показано на Рис. $4 \mathrm{~b}$ скорость износа образцов находилась в диапазоне от $6 \times 10^{-9}$ до $84 \times 10^{-9} \mathrm{Mm}^{3} / \mathrm{Hм}$

Табл. 4. Коррозионные параметры покрытий.

Table 4. Corrosion parameters of coatings.

\begin{tabular}{|c|c|c|c|c|c|c|}
\hline \multirow[t]{2}{*}{ Параметры/Parameter } & \multicolumn{6}{|c|}{ Образцы/Samples } \\
\hline & Ti6AlV & AT1 & AT2 & AT3 & AT4 & AT5 \\
\hline$I_{\text {corr }}, \mu \mathrm{A} / I_{\text {corr }}, \mathrm{MKA}$ & 2.86 & 4.59 & 6.76 & 2.94 & 3.48 & 3.43 \\
\hline$R_{\mathrm{p}}, \mathrm{kOhm} / R_{\mathrm{p}}, \mathrm{KOM}$ & 586 & 385 & 220 & 690 & 1141 & 990 \\
\hline$E_{\text {corr }}, \mathrm{V} / E_{\text {corr }}, \mathrm{B}$ & -0.52 & -0.55 & -0.42 & -0.51 & -0.75 & -0.86 \\
\hline
\end{tabular}

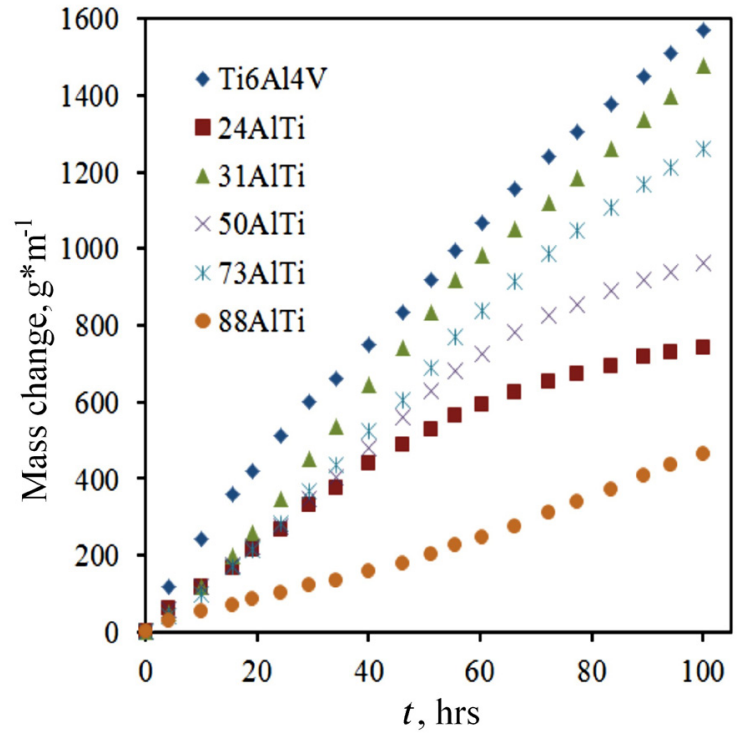

a

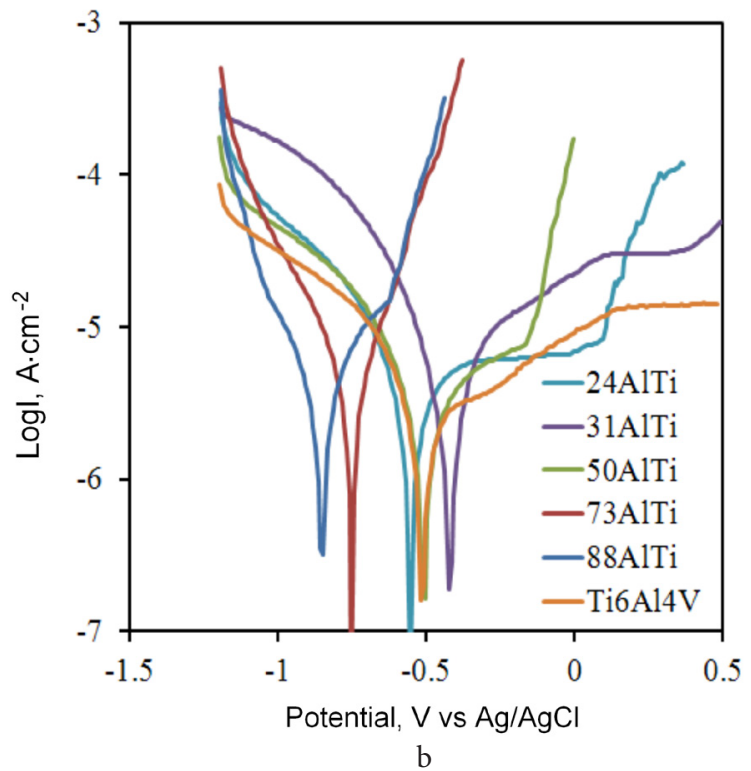

b

Pис. 3. (Color online) Циклическая жаростойкость при $900^{\circ} \mathrm{C}$ (а) и потенциодинамические поляризационные кривые (b) покрытий.

Fig. 3. (Color online) Cyclic oxidation resistance at $900^{\circ} \mathrm{C}$ (a) and potentiodynamic polarization curves (b) of coatings. 


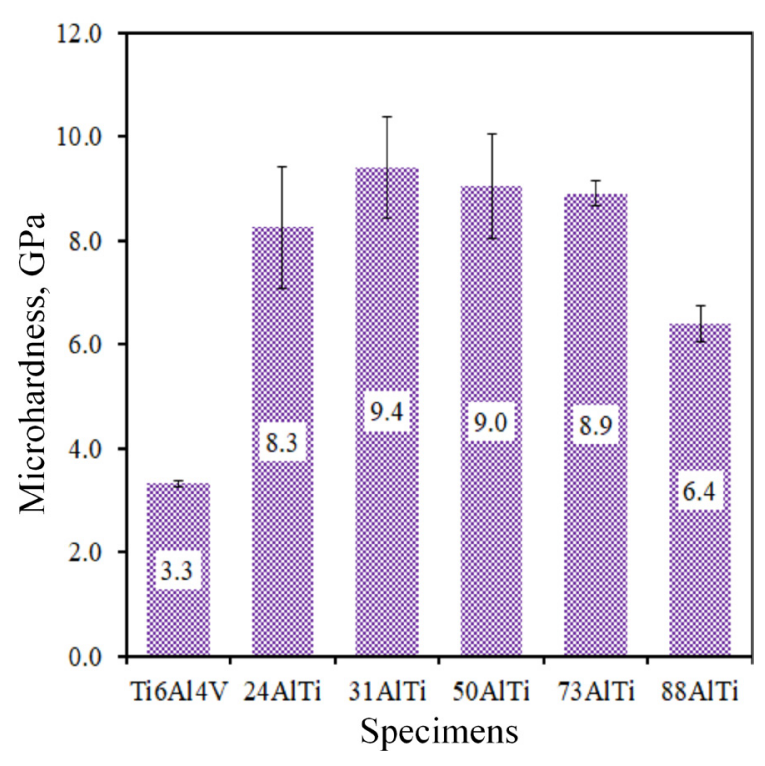

a

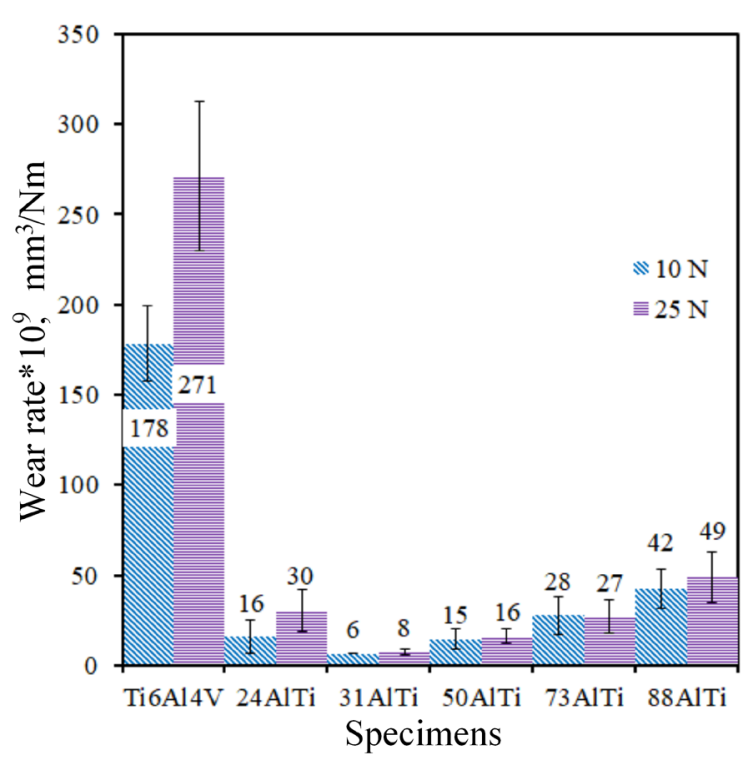

b

Pис. 4. (Color online) Микротвердость (а) и скорость износа (b) образцов.

Fig. 4. (Color online) Microhardness (a) and wear rate (b) of samples.

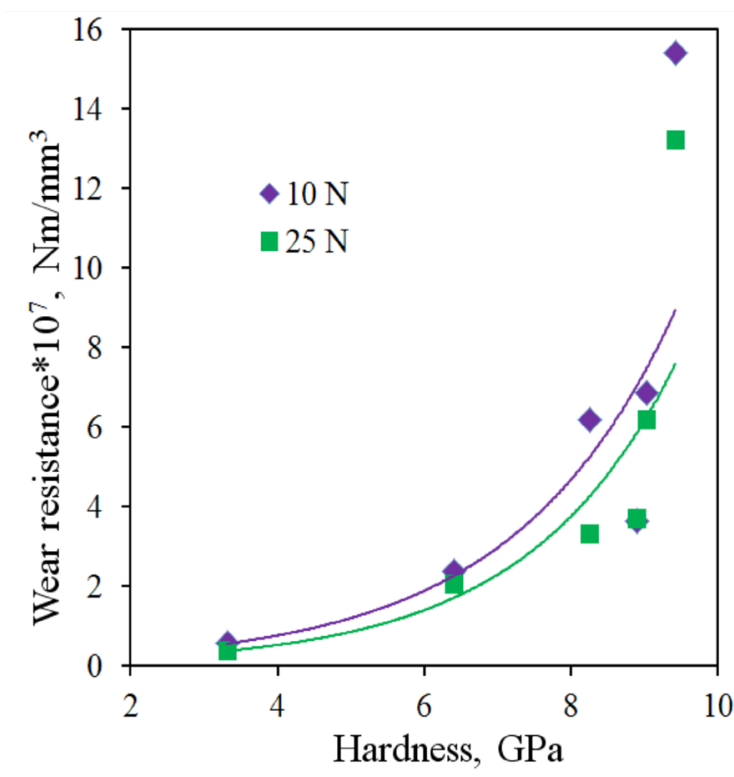

Puc. 5. (Color online) Зависимость износостойкости Ti-Al покрытий от их твердости.

Fig. 5. (Color online) Relationship between hardness and wear resistance for Ti-Al coatings.

и от $8 \times 10^{-9}$ до $49 \times 10^{-9} \mathrm{Mм}^{3} /$ Нм при нагрузках 10 и $25 \mathrm{H}$, соответственно. Средние значения износостойкости покрытий были в 4 - 36 раз выше, по сравнению со сплавом Ti6Al4V. С ростом содержания алюминия скорость изнашивания образцов изменялась немонотонным образом, достигая наименьшего значения у образца 31AlTi. Далее она повышалась с ростом содержания алюминия до 88 ат.\%. В целом данные по износу хорошо соотносятся с твердостью образцов. В соответствии с законом Архарда повышение твердости материала снижает скорость его износа [21]. Рис. 5 это наглядно иллюстрирует, причем эта зависимость для Ti-Al покрытий носит экспоненциальный характер.

\section{4. Выводы}

Коррозионные свойства покрытий в 3.5\% растворе $\mathrm{NaCl}$ имели близкие характеристики со сплавом Ti6Al4V. Образцы с покрытиями позволяют повысить жаростойкость сплава Ti6Al4V при температуре $900^{\circ} \mathrm{C}$ в 1.1-3.4 раза. Лучшую жаростойкость показало покрытие с наибольшим содержанием алюминия. Микротвердость покрытий находилась в диапазоне 6.4 - 9.4 ГПа. Покрытия с более близким соотношением титана к алюминию обладали наибольшей твердостью. Скорость износа покрытий при сухом трении была в 4-36 раз ниже, чем у сплава Ti6Al4V. При этом, она повышалась с ростом концентрации алюминия в покрытиях.

Благодарности/Acknowledgments. Исследование выполнено за счет гранта Российского научного фонда (проекm №19-73-00031). / The study was carried out with a grant from the Russian Science Foundation (project No. 19-73-00031).

\section{Литература/References}

1. R. Sitek, J. Kaminski, J. Borysiuk, H. Matysiak, K. Kubiak, K. J. Kurzydlowski. Intermetallics. 36, 36 (2013). Crossref

2. M. Gizynski, S. Miyazaki, J. Sienkiewicz, S. Kuroda, H. Araki, H. Murakami, Z. Pakiela, A. Yumoto. Surf. Coat. Technol. 315, 240 (2017). Crossref

3. Q. Jia, D. Li, Z. Zhang, N. Zhang, W. Zhao. Mater. Res. Exp. 6, 096408 (2019). Crossref

4. C. J. Wang, P. K. Koech, X.Z. Lin. Journal of the Chinese. Institute of Engineers, Transactions of the Chinese Institute of Engineers, A. 42, 244 (2019). Crossref

5. S. PalDey, S. C. Deevi, T. L. Alford. Intermetallics. 12, 985 (2004). Crossref

6. I. A. Kurzina, E. V. Kozlov, Y.P. Sharkeev, A. I. Ryabchikov, 
I. B. Stepanov, I. A. Bozhko, M. P. Kalashnikov, D. O. Sivin, S.V. Fortuna. Surf. Coat. Technol. 201, 8463 (2007). Crossref

7. B. Guo, J. Zhou, S. Zhang, H. Zhou, Y. c. Pu, J. Chen. Appl. Surf. Sci. 253, 9301 (2007). Crossref

8. K.E. Machethe, A.P.I. Popoola, D.I. Adebiyi, O. S. I. Fayomi. Proc. Manuf. 7, 549 (2017). Crossref

9. A. A. Burkov. Lett. Mater. 5 (4), 371 (2015). (in Russian) [А.А. Бурков. Письма о материалах. 5 (4), 371 (2015).] Crossref

10. A. D. Verkhoturov. Russ. Engng. J. 56, 45 (1976).

11. A.D. Verkhoturov, L.M. Murzin. Soviet Powder Metallurgy and Metal Ceramics. 12, 680 (1973). Crossref

12. S. A. Pyachin, A. A. Burkov, V. S. Komarova. J. Surf. Invest. 7 (3), 515 (2013). Crossref

13. D. V. Lazurenko, I. A. Bataev, I.S. Laptev, A. A. Ruktuev, I.N. Maliutina, M.G. Golkovsky, A.A. Bataev. Mater. Charact. 134, 202 (2017). $\underline{\text { Crossref }}$
14. A. A. Burkov, S.A. Pyachin, V. O. Krutikova. Hardening technologies and coatings. 15 (10), 451 (2019). (in Russian) [А.А. Бурков, С. А. Пячин, В.О. Крутикова. Упрочняющие технологии и покрытия. 15 (10), 451 (2019).]

15. A.A. Burkov, P. G. Chigrin. Surf. Coat. Technol. 351, 68 (2018). Crossref

16. X. L. Zhang, Z.H. Jiang, Z.P. Yao, Y. Song, Z. D. Wu. Corros. Sci. 51, 581 (2009). Crossref

17. Ł. Maj, J. Morgiel, K. Mars, G. Cios, A. Tarasek, E. Godlewska. Mater. Charact. 154, 31 (2019). Crossref

18. S.-G. Liu, J.-M. Wu, S.-C. Zhang, S.-J. Rong, Z.-Z. Li. Wear. 262, 555 (2007). Crossref

19. Y. Liu, W. Liu, Y. Ma, C. Liang, C. Liu, C. Zhang, Q. Cai. Surf. Coat. Technol. 353, 32 (2018). Crossref

20. C. Zhang, M. Zheng, Y. Wang, P. Gao, B. Gan. Surf. Coat. Technol. 378, 124821 (2019). Crossref

21. T. Telliskivi. Wear. 256, 817 (2004). $\underline{\text { Crossref }}$ 